\title{
Aplicação Mobile para Automatização do Registro de Presença de Estudantes
}

\author{
Luyara Rufino Ajiki \\ Inst. Federal de Mato Grosso do \\ Sul \\ Campo Grande, MS, Brasil \\ luyara.ajiki@gmail.com
}

\author{
Munir Souza dos Santos \\ Inst. Federal de Mato Grosso do \\ Sul \\ Campo Grande, MS, Brasil \\ munir.ifms@gmail.com
}

\author{
Luiz Fernando Delboni \\ Lomba \\ Inst. Federal de Mato Grosso do \\ $\mathrm{Sul}$ \\ Campo Grande, MS, Brasil \\ luiz.1omba@ifms.edu.br
}

\begin{abstract}
Since attendance monitoring and recording plays a key role in the school environment, especially regarding the duties of students and guardians, the purpose of this paper was to develop a mobile application to automate student attendance recording using Near Field Communication technology. (NFC). Students record their presence by approaching an NFC tag (present on ID badges) from a teacher's mobile device, which receives identification data from the students present. This verification method is an additional option for making calls and enables recorded data to be exported and used in the school's academic system.
\end{abstract}

\section{KEYWORDS}

Presence Control, Automation, NFC

\section{INTRODUÇÃO}

Como maneira de assegurar e organizar a permanência das crianças e jovens na escola, faz-se indispensável o registro de presenças dos estudantes. O registro é de responsabilidade da escola (Lei $n^{\circ} 9.594$ de 20 de dezembro de 1996) [1] e serve como instrumento para auxiliar a comunicação aos responsáveis dos estudantes quanto a frequência (Lei $\mathrm{n}^{\circ} 12.013$, de 6 agosto de 2009, que altera o Artigo 12 da Lei $n^{\circ}$ 9.394) [2]. Assim como, notificar o Conselho Tutelar quando o estudante atinge a porcentagem máxima de ausências permitidas (Lei $\mathrm{n}^{\circ} 13.805$ de 10 de janeiro de 2019, que altera dispositivo da Lei $n^{\circ} 9.394$ ) [3].

Visto isso, é importante que o registro de presença dos estudantes seja realizado diariamente em todas as aulas. Atualmente, são utilizadas diversas formas de preenchimento da lista de presença no Instituto Federal de Mato Grosso do Sul (IFMS), dentre as quais destacamos (1) o registro em papel realizado pelo próprio professor, após chamar o nome e sobrenome do estudante, e o (2) registro manual realizado diretamente pelos estudantes, em uma folha de papel distribuída.

Os dois métodos trazem a desvantagem de exigir que o professor transcreva os dados para o sistema acadêmico digital. A chamada nominal ainda possui a desvantagem do tempo despendido para concluir a verificação das presenças, que pode levar cerca de 10 minutos de cada aula [4].
Ademais, podem ocorrer situações em que o diário com a frequência estudantil não esteja atualizado, ou seja, o professor não ter realizado o lançamento das presenças no sistema acadêmico, ocasionando contratempos quanto a verificação da frequência dos estudantes.

Portanto, assim como há a necessidade do controle de presença dos estudantes, há a possibilidade de automatização deste processo, facilitando o trabalho do professor e melhorando a disponibilidade dos dados. Porém, é importante buscar uma solução de simples implementação e de baixo custo, tornando viável sua implantação na instituição.

Dessa forma, a proposta deste trabalho foi desenvolver um sistema que faça o registro automático da presença dos estudantes, por meio da troca de informações entre um dispositivo que possua a tecnologia Near Field Communication (NFC) e uma tag NFC presente nos crachás dos estudantes.

\section{SOLUÇÃO PROPOSTA}

A solução proposta visa automatizar o registro de presenças estudantis, ou seja, sem que os docentes tenham que efetuá-las de forma manual. Sendo assim, esse método de verificação é uma opção adicional à realização das chamadas atuais, podendo os professores utilizarem os métodos tradicionais já citados ou o sistema aqui proposto.

O sistema é constituído de duas partes:

Módulo administrativo: implementado em versão web, a qual somente os administradores do sistema terão acesso, podendo realizar os cadastros, leituras, edições e exclusões quando necessário. Nesta parte foram utilizadas as linguagens PHP e HTML, e para o design o framework Bootstrap, combinando o uso do CSS para estilizar a aplicação.

Módulo para registro das presenças: desenvolvido em uma versão mobile que será disponibilizada aos docentes do IFMS, para a realização do registro de presenças estudantis. Em seu processo de implementação foi utilizado o framework PhoneGap/Cordova ferramenta que possibilita o desenvolvimento de aplicações multiplataforma - utilizando a linguagem JavaScript, juntamente com a de marcação HTML e de estilo CSS. Para conexão com o banco de dados (MySQL) e demais ações do sistema, foi utilizado o jQuery. 
O fluxograma da Figura 1 mostra a visão geral do sistema, na qual o docente ativa o aplicativo em seu smartphone (que deve possuir a tecnologia NFC). Na sequência, os alunos podem validar sua presença, aproximando seu crachá (que contém uma tag NFC) ao dispositivo do professor. Por conseguinte, depois da realização do registro das presenças, os docentes farão o encerramento do mesmo, gerando a lista de alunos presentes a ser enviada e importada no sistema acadêmico da instituição.

A escolha pela utilização da NFC deu-se por tratar de uma tecnologia que possibilita a troca de informações sem uso de fios e sem que haja contato entre os dois dispositivos que possua a tecnologia, por meio de radiofrequência [5]. Além disso, a mesma está crescendo rapidamente entre os dispositivos móveis da atualidade, no qual fabricantes têm adicionado esta tecnologia em seus projetos [6].

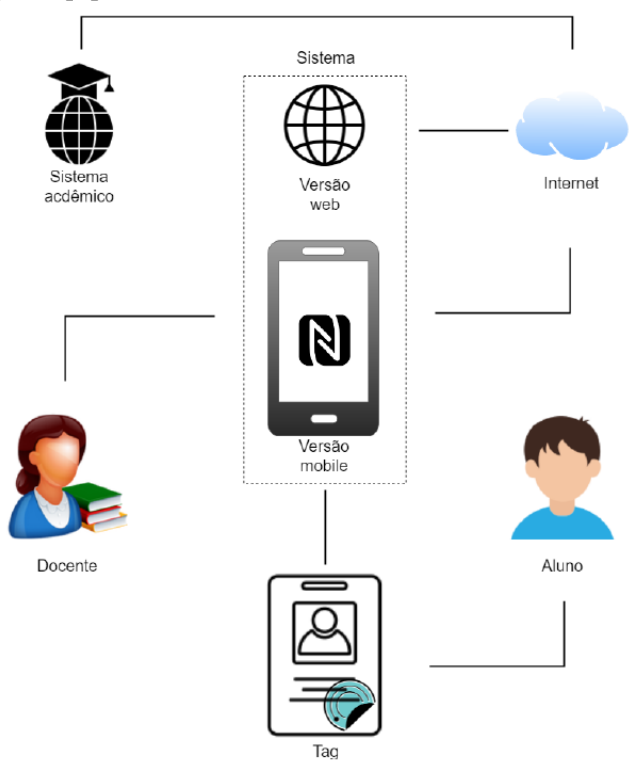

Figure 1. Visão Geral do Sistema Proposto

A utilização dessa tecnologia também está se popularizando em vários setores do mercado, sendo utilizado para realização de transações financeiras, pagamentos, e entrada de pessoas em eventos [7]. No Brasil, alguns cidadãos já vivenciam a experiência de utilização da NFC, no qual o smartphone substitui o validador de bilhetes de ônibus e permite o pagamento de corridas de táxi [8].

\section{DESENVOLVIMENTO}

Para a realização do levantamento de requisitos foi realizada uma entrevista informal com alguns professores da instituição, onde foi abordado sobre o que os mesmos gostariam que estivessem presentes em uma aplicação mobile para realização do registro de presenças.
Para documentar e descrever as funcionalidades do sistema, foi elaborado o diagrama de caso de uso, conforme apresentado na Figura 2.

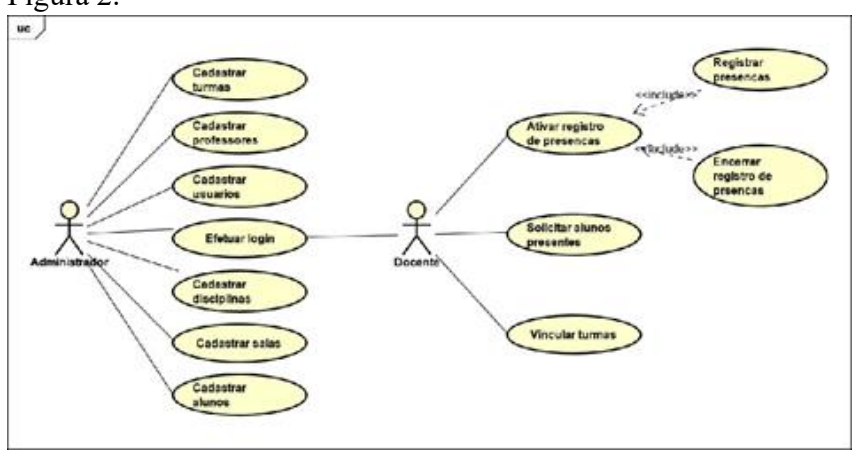

Figure 2. Diagrama de caso de uso

No módulo administrativo, que roda como uma aplicação Web, foram implementadas os casos de uso do usuário Administrador. A partir destas funcionalidades são inseridos todos os dados necessários para que o usuário Docente utilize o sistema.

A primeira página, ao acessar o sistema, direciona o usuário para tela de login, onde é solicitado nome de usuário e senha. Após efetuar o login, o usuário é direcionado para tela de administrador, onde possui as opções de cadastro e visualização dos dados.

Na tela Cadastrar, apresentada na Figura 5, estão disponíveis todos os cadastros do sistema: usuário, aluno, professor, disciplina, turma e sala. $\mathrm{Na}$ opção Visualizar, o usuário pode listar, alterar ou remover algum registro dos cadastros.

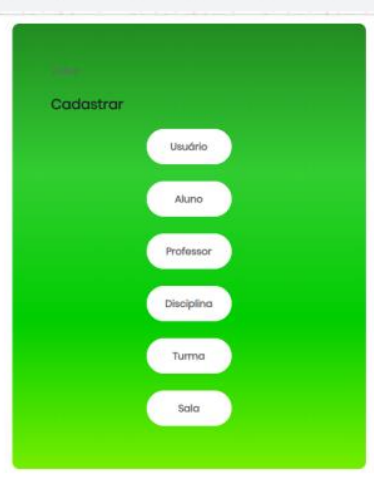

Figure 3. Tela de cadastro do módulo administrativo

A versão do sistema para utilização pelo professor é o módulo de registro das presenças. Esta versão está disponível para uso em dispositivos móveis e as funções são acessadas após o usuário se autenticar no sistema, com seu login e senha (Figura 4). O professor pode vincular novas turmas, ativar/desativar o registro de presenças, além de consultar o relatório de alunos presentes por aula.

Para iniciar o registro das presenças, o professor deve selecionar o diário da turma que deseja realizar a chamada (Figura 
5). Os diários são previamente cadastrados pelo próprio professor, que deve apenas informar a turma e a disciplina a qual o diário estará vinculado.

Por fim, na Figura 6, pode-se observar a tela que indica o sistema ativo para registro das presenças, com o número de presenças registradas e a opção para encerrar os registros.

\section{CONSIDERAÇÕES FINAIS}

Este trabalho apresentou o desenvolvimento de uma aplicação mobile para registro de presença de estudantes, com o objetivo de sistematizar a coleta e o armazenamento dos registros de presença no IFMS.

O módulo administrativo, para realizar o cadastro dos dados iniciais para uso da aplicação, está pronto, enquanto o módulo para registro das presenças está na fase de finalização das telas do usuário. A próxima fase será a implementação das funções do módulo NFC, que permitirá a comunicação do sistema com o crachá dos estudantes.

A solução aqui apresentada possui vantagens, uma vez que, não há custo adicional à escola, exceto a aquisição das tags NFC para



Figure 4. Tela de login do aplicativo na versão mobile

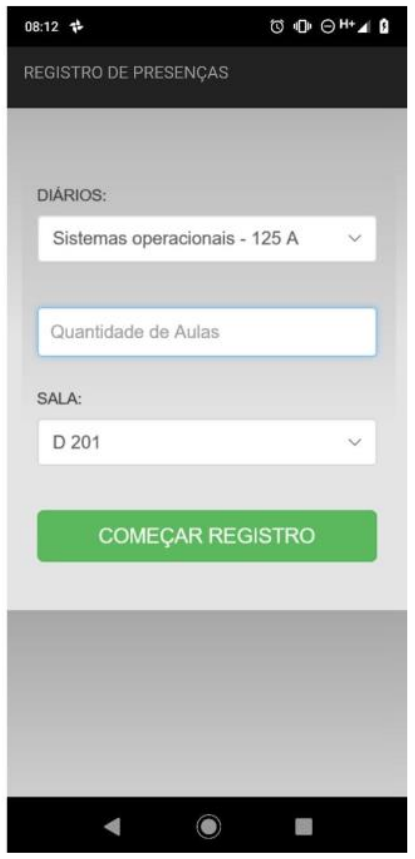

Figure 5. Tela de configuração para início do registro das presenças

integração aos crachás dos estudantes. Porém, um problema para efetivar o uso do sistema é a necessidade do professor possuir um dispositivo com tecnologia NFC.



Figure 6. Tela de registro das presenças 
XI Computer on the Beach

Como proposta de continuidade, deve-se testar a integração do software com o sistema acadêmico atualmente utilizado na instituição e a criação de uma funcionalidade para emissão de alertas sobre a frequência dos estudantes aos seus responsáveis e/ou assistentes de alunos.

\section{REFERÊNCIAS}

[1] Brasil. Estabelece as diretrizes e bases da educação nacional. Lei no 9.394, de 20 de dezembro de 1996, Presidência da República, Brasília, 1996.

[2] Brasil. Altera o art. 12 da lei no 9.394, de 20 de dezembro de 1996 , determinando às instituições de ensino obrigatoriedade no envio de informações escolares aos pais, conviventes ou não com seus filhos. Lei $\mathrm{n}^{\circ} 12.013$, de 6 de agosto de 2009, Presidência da República, Brasília, 2009.

[3] Brasil. Altera dispositivo da lei $\mathrm{n}^{\circ}$ 9.394, de 20 de dezembro de 1996, para obrigar a notificação de faltas escolares ao conselho tutelar quando superiores a $30 \%$ (trinta por cento) do percentual permitido em lei. Lei $\mathrm{n}^{\circ} 13.803$, de 10 de janeiro de 2019, Presidência da República, Brasília, 2019.

[4] Vaishali Ghodekar, Aboli Kute, Swati Patil, and Prof.Ritesh Thakur. Automated attendance system with rfid through smart card. International Journal of Engineering Research Technology (IJERT), 2(10), 2013. ISSN 2278-0181.

[5] T. Igoe, Don Coleman, and Brian Jepson. Beginning NFC: near field communication with Arduino, Android, and Phonegap. O'Reilly Media, 2014.

[6] Paula Hunter. The time for nfc is now. URL https://nfc-forum.org/post-inblogtest-2.

[7] Jairo Tomaszewski and Daniel Formolo. Nfc aplicado a sistemas de controle de entrada em eventos. Cadernos do IME - Série Informática, 37, 03 2017. doi: 10.12957/cadinf.2016.13706

[8] Damien Bullot. A força do nfc e sua consolidação no brasil. URL https://www.mobiletime.com.br/noticias/02/10/2013/a-forca-do-nfc-e-suaconsolidacao-no-brasil/. 